\title{
O Presidente Emílio Médici Institui o Programa de Infegraçĩo Social
}

\section{DISCURSO. 2. MENSAGEM AO CONGRESSO}

NACIONAL. 3. LEI COMPLEMENTAR No 7/70.

O Presidente Garrastazu Médici fêz, no Palácio das Laranjeiras, através de uma cadeia nacional de rádio e televisão, um nôvo apêlo à união dos brasileiros, e sancionou a lei que institui - Fundo de Participação.

\section{O DiscuRso}

Foram as seguintes as palavras do Presidente Médici:

"Homens de minha pátria.

Manhã, tarde, noite dêste 7 de Setembro, o primeiro para mim tão diferente, três vêzes me é dado celebrar $a$ independência.

Primeiro, perante o povo na rua, vendo o povo fardado desfilar a altivez de todos nós. Desfraldadas nas lanças da eterna Cavalaria, ali vi, nas bandeiras históricas, o sôpro das gerações. Vi, à frente dos batalhões, a bandeira que nos une a todos nós. A mesma bandeira vi, onipresente, na mão atenta do menino erguido nos ombros e no carinho de seu pai, na ânsia de sua emoção. Vi a bandeira nos olhos da multidão.

A hora da independência, passei-a junto a Deus. No altar erguido em prece, no Monumento aos Mortos da II Grande Guerra, rezei pela vida e pela paz de todos nós. E, nos fiéis ajoelhados nos patamares que ascendem ao monumento dos pracinhas, cuidei ver os degraus todos da escalada nacional: a independência, a soberania, a emancipação. E senti que, naquela hora e em todo o Brasil, aquêles olhos e aquela emoção rezavam o mesmo credo de homens da mesma pátria.

Agora, pela terceira vez celebrando - dia, quis estar na familia de meu Govêrno, nesta ceia da independência e, junto a esta família, chegar a tôda a familia brasileira, nesta hora de familia reunida. E porque quero que me tenham integrado à minha equipe, solidário e não solitário, regente e não solista, aqui chamei meus Ministros, para que, povo e Govêrno, sob a mesma luz de inspiração da independência, celebremos juntos, no Dia da Pátria, o mesmo amor à pátria.

Queremos, assim irmanados, dizer ao povo o amor à pátria como entendemos e o amor à pátria como năo conseguimos entender.

O amor à pátria que o Govêrno entende não se faz só de palavras e evo- 
cações, nem se esgota nas emoções à flor da pele; que o amor à pátria que entendemos é feito mais no fundo da gente; amor à pátria que é propósito, que é atitude e é constância; amor à pátria que é determinação e coragem de promover esta terra e êste povo.

CONVERGENCIA

Não consigo ver o amor à pátria nos homens e nas coisas onde encóntro a vaidade e o desperdício, o egoísmo e a cupidez, a falsidade e a hipocrisia, a vanglória e a ostentação, a fuga e o liberticídlo, a desesperança e a frustração, a inveja e a arrogância; mas encontro sempre o amor à pátria nos tempos e nos lugares onde prova a convergência e a solidariedade humana; a verdade e a renúncia; a responsabilidade, a confiança e a altivez.

O amor à pátria que entendemos 6 - que almeja desenvolvê-la e enriquecê-la para que se alcance o bem-estar de tôda a nossa gente, e que só quer nosso país poderoso e forte para garantir nosso destino e contribuir para a justiça entre os homens $e$ as naçöes.

Não consigo ver qualquer centelha dêsse amor nos homens que, aferrados a axiomas e postulados, perseguem distorcidas idealidades. Não entendo patriotas êsses poucos fanatizados que tentam impor os seus desígnios à imensa maioria dos brasileiros, ainda que por isso sangre o povo, ainda que se alongue o tempo perdido ou mesmo que se sacrifique uma geração.

Não consigo ver êsse amor em quem se volta contra a sua pátria; quem a quer em tudo derrotada e denegrida; quem se desespera com o advento da ordem e da prosperidade, na torpe estratégia do quanto pior melhor.
O amor à pátria que entendemos é o que integra terras e homens, e o que formula soluções brasileiras para $\circ$ desenvolvimento e a justiça social. 0 patriotismo que entendemos é o que procura construir uma sociedade, em que todo homem alcance nível mínimo de bem-estar que lhe baste à vida, em que seja livre para participar da obra coletiva, e em que qualquer um possa fazer a colheita justa da sua iniciativa e do seu trabalho.

\section{PROMOÇÃO}

O amor à pátria que entendemos é aquêle que, vendo a pátria em cada um dos números do nosso imenso potencial humano, não aceita que alguém os considere simples números, senão porque exige que todos os respeitem como homens.

E considerando a pátria em cada homem nosso, o patriotismo dêste Govêrno não pode tolerar que, marginalizados pela ignorância e a pobreza, não contem ao nosso lado tantos $\mathrm{mi}$ Ihões de brasileiros. Mas o amor à pátria como entendemos, assim não se conformando, em vez de se refugiar na desesperança e na revolta inoperantes, desperta a consciência nacional, busca o tempo perdido e o caminho que antes não se encontrou, para fazer mais solidários os caminhos de todos os homens.

O amor à pátria como entendemos é o silencioso ofício de todo homem de bem, que ama a lei e a ordem, e que, construindo o seu destino e o dos seus também se faz responsável e participante nos destinos de seu país.

Êsse, o sentimento patriótico que o meu Govêrno entende e que alegra o coração do povo neste 7 de Setembro. A êle me dou por inteiro, vendo passar mais um aniversário da pátria in- 
dependente, com a esperança renovada e a certeza de que estamos no caminho certo do apressamento do futuro.

Quero confidenciar aos homens de meu país as maiores alegrias que encheram o coração do Presidente nesta Semana da Pátria.

Quero dizer ao povo que nunca, como neste ano, vi festejar-se, assim, a nossa Independência, em tôda a extensão do território nacional, com essa efusão e essa presença. E cuido que, sôbre ser um eco ainda do justo orgulho do povo pela recente vitória desportiva, estamos diante de um sinal e de um estado de espírito. Dizme a sensibilidade que êste é um sinal de que desperta e se fortalece a vontade coletiva, estado de espírito indispensável ao desenvolvimento de uma nação.

\section{INTEGRAÇÃO}

Confesso também a alegria dos novos passos pela nossa integração. Começou a fase executiva do Programa de Integração Nacional e, graças à prestância e à presteza com que o Congresso Nacional votou o projeto, já se encontra, em minhas mãos para ser promulgada, o que farel ainda esta noite, a lei que institui o Fundo de Participação, instrumento primeiro da integração social de nosso povo.

Venho dizer-lhe também minha alegria por sentir, neste Dia da Pátria, quanto mais unidos estamos desde que se lançou meu nome à sucessão do Presidente Costa e Silva. Desde a primeira hora, tôdas as vêzes em que falei à nação, fiz o chamamento à união. Cheguei mesmo, no Natal, a me voltar também para os contrários, os discordantes, os indiferentes e os crestados pela desesperança.
Se alguém me teve irrealista e sonhador, peço que, neste Dia da Pátria, se faça justiça, não sòmente à esperança, à participação, à concórdia e ao consenso que dia a dia vêm chegando, mas também que se faça justiça a todos os brasileiros que ouviram aquêle chamamento.

Por entre as emoções dêste grande dia, quero alertar a nação contra os excessos do otimismo fácil, pois a euforia, como o desalento, também pode ser maléfica. Manda meu amor à verdade que eu diga ao povo que hoje é muito mais forte a minha confiança no sucesso da mais difícil das minhas missões, porque sinto consolidar-se nossa situação econômico-financeira, porque vejo se firmar um ritmo nôvo de desenvolvimento, porque vejo os homens começando a se compreenderem e, sobretudo, porque recolho, em minha alma, a generosa compreensão dos meus compatriotas.

Com êsse prêmio que tanto me faz bem, com a certeza de que nos uniremos mais e com a confiança cada vez mais forte na viabilidade desta pátria que hoje festejamos, renovo o meu compromisso de servir à sua emancipação, e o meu propósito de oferta das energias, que Deus ainda me der, à causa da felicidade de meu povo."

MENSAGEM No 13 , DE 1970 (CN)

\section{(No 258/70, na origem)}

\section{Excelentíssimos Senhores Membros} do Congresso Nacional

Ao assumir a Presidência da República, proclamei minha fé no homem e no povo, apontando no desenvolvimento uma atitude coletiva, que requer 
a mobilização total da opinião pública.

$\mathrm{Na}$ mensagem ao Congresso Nacional, afirmei que o Govêrno não compreende a prática da justiça social senão em têrmos de distribuição da riqueza global e tudo pretende fazer para que o desenvolvimento econômico seja simultâneo com a promoção social dos trabalhadores e não dê ensejo à formação de castas ou classes privilegiadas, mas represente a oportunidade para que o nivel de poder aquisitivo dos assalariados os torne cada dia mais participes da riqueza comum da Nação.

Fiel a êsses princípios, acentuei, no mesmo documento, o timbre profundamente humanista da política social do Govêrno, que contempla o homem empregador ou empregado - como um fim e não como um meio, para que - trabalho seja não só trabalho do homem, mas trabalho em prol do homem.

Em reunião ministerial de seis de janeiro último, ao traçar normas para meus auxiliares diretos, orientava-lhes a ação no rumo da justiça social, lembrando que "sem quebra do desenvolvimento econômico do País, cujo ritmo se deve, não só manter, mas, ainda, acelerar tanto quanto possivel, impõese, concomitantemente, a adoção de medidas pelas quais se venha a distribuir a renda global de modo mais equânime, a fim de que tôdas as camadas da população seja beneficiadas pelo aumento da riqueza comum".

Em consonância com tais pensamentos, que definem diretrizes fundamentais do Govêrno, preconizei a expansão da economia nacional, sem a qual jamais chegaremos a ter uma poupança nossa, que nos torne menos dependentes e acione, com o nosso esfôrço, aliado à ajuda externa, um grande projeto nacional de desenvolvimento.

Queria; assim, tornar bem claro que o fortalecimento da estrutura das emprêsas, pela preservação de sua rentabilidade, suscita a união das energias do trabalhador e do talento empresarial, constituindo fórmula prática para a permanente e indispensável harmonia entre o capital e o trabalho.

A participação de todos no produto nacional, a criaçăo de estímulos para a melhoria da remuneração dos trabaIhadores, o incremento da poupança individual para a formação de patrimônio, que garanta a cada brasileiro um futuro melhor, tornaram-se, por isso, a minha preocupação constante e justificam plenamente o Projeto de Lel que ora submeto à aprovação do Congresso Nacional, nos têrmos do artigo 51, parágrafo $2{ }^{\circ}$, da Constituição.

Institui êsse projeto o Programa de Integração Social, que abrirá caminho para a organização de uma sociedade aberta, de cuja vida e crescimento todos participem.

Govêrno, empresários e empregados se associam, pela conjugação permanente de suas fôrças, de seus recursos e do produto de seu trabalho, para um único fim - o de instaurar uma sociedade integrada, na qual seja uma realidade, e não um mito, a justiça social. Prevê o projeto, como meio adequado para o Programa de Integração Social, um Fundo de Participação, constituído por depósitos efetuados pelas emprêsas na Caixa Econômica Federal.

O Fundo de Participação resulta de deduções no impôsto de renda e de 
recursos próprios das emprêsas, de tal sorte e em tal proporção que nenhum sacrificio ponderável se impõe a essas mesmas emprêsas.

Cada empregado do setor privado, de tôda e qualquer emprêsa, em tôda a extensão do território nacional, será possuidor de uma Caderneta de Participação, que the conferirá o direito de, em proporção com os salários recebidos e o tempo de serviço, participar, efetivamente, de um fundo global, cuja fonte única não é a emprêsa, pois também o Govêrno abre mão, em prol do Programa de Integração Social, de uma parcela de sua receita.

A movimentação do Fundo, que, por seu turno, virá beneficiar as emprêsas, ampliando-lhes as possibilidades de investimento $e$ até proporcionando-Ihes maior volume de capital de giro, redundará em benefício para cada empregado, graças à correção monetária e aos juros dos depósitos nominais, anualmente percebidos, além da possibilidade de utilizaçăo total dos depó. sitos em ocasiōes e circunstâncias que - Projeto de Lei estabelece, inclusive para aquisiçăo de casa própria.

Tive em mira, muito especialmente, levando em conta a necessidade de imprimir um sentido formativo e pedagógico a essa iniciativa, incentivar uma política realista de estímulo à formaçăo do patrimônio individual. Não me deixei impressionar, senão naquilo que se me afigurou digno de imitação, por modelos estrangeiros, nem cedi à tentaçăo de enfrentar problemas que alguns sociólogos e economistas já compararam à quadratura do circulo.

Permitam-me, portanto, os Senhores Membros do Congresso Nacional salientar a originalidade da fórmula en- contrada, que, pragmática e objetiva, atende ainda ao mais alto fim visado - a integração social dos brasileiros, pela participação de todos no produto nacional.

- Programa de Integração Social, objeto da proposição que ora submeto ao Congresso Nacional, valoriza o empregado, fortalece a emprêsa e engrandece o Brasil.

Brasilia, 20 de agôsto de 1970. Emílio G. Médici, Presidente da República.

- Programa de Integração Social, que apanhou o país de surprêsa e levou à administração federal a comovida solidariedade de representantes de tôdas as classes, representou, admitem todos, a abertura revolucionária para a participação dos trabalhadores no crescimento das emprêsas e no progresso nacional.

Com uma sociedade aberta e equânime, o pais retomou o ritmo de desenvolvimento que as crises políticosociais haviam pôsto em quarentena e o Govêrno assumiu, de fato, o contrôle de todos os esquemas que visam à prosperidade das classes sociais.

Isto, graças ao Programa de Integração Social, cuja Lei Complementar é, na integra, a seguinte:

LEI COMPLEMENTAR No 7 , DE 7 DE SETEMBRO DE 1970.

Institui o Programa de Integração Social, e dá outras providências.

\section{O Presidènte da República}

Faço saber que o Congresso $\mathrm{Na}$ cional decreta e eu sanciono a seguinte Lei Complementar:

Art. 19 E instituido, na forma prevista nesta Lei, o Programa de In- 
tegração Social, destinado a promiover a integração do empregado na vida e no desenvolvimento das emprêsas.

§ 19 Para os fins desta Lel, entende-se por emprêsa a pessoa jurídica, nos têrmos da legislação do Impôsto de Renda, e por empregado todo aquêle assim definido pela legislação trabalhista.

§ 20 A participação dos trabalhadores avulsos, assim definidos os que prestam serviços a diversas emprêsas, sem relação empregatícia, no Programa de Integração Social, far-se-á nos têrmos do Regulamento a ser baixado, de acôrdo com o artigo 11 desta Lei.

Art. 2\% O Programa de que trata - artigo anterior será executado mediante Fundo de Participação, constituido por depósitos efetuados pelas emprêsas na Caixa Econômica Federal.

Parágrafo único. A Caixa Econômica Federal poderá celebrar convênios com estabelecimentos da rêde bancária nacional, para o fim de receber os depósitos a que se refere êste artigo.

Art. 3ํ $\mathrm{O}$ Fundo de Participação será constituído por duas parcelas:

a) a primeira, mediante dedução do Impôsto de Renda devido, na forma estabelecida no § 1ơ, dêste artigo, processando-se o seu recolhimento ao Fundo juntamente com o pagamento do impôsto de Renda;

b) a segunda, com recursos próprios da emprêsa, calculados com base no faturamento como segue:

1) no exercício de $1971,0,15 \%$;

2) no exercício de $1972,0,25 \%$
3) no exercício de 1973, 0,40\%;

4) no exercício de 1974 e subseqüentes, $0,50 \%$.

$\S 1$ ị A dedução a que se refere a alínea "a" dêste artigo será feita sem prejuizo do direito de utílização dos incentivos fiscais previstos na legislação em vigor e calculada com base no valor do Impôsto de Renda devido, nas seguintes proporções:

a) no exercício de $1971 \ldots 2 \%$;

b) no exercício de $1972 \ldots 3 \%$;

c) no exercício de 1973 e subseqüentes ................. $5 \%$

$\S 2$. As instituiçōes financeiràs, sociedades seguradoras e outras emprêsas que não realizam operações de vendas de mercadorias particlparäo do Programação de Integração Soclal com uma contribuição ao Fundo de Participação de recursos próprios de valor idêntico do que fôr apurado na forma do parágrafo anterior.

$\S 3$ ํ. As emprêsas que, a título de incentivos fiscais, estejam isentas, ou venham a ser isentadas, do pagamento do Impôsto de Renda, contribuirão para o Fundo de Participação, na base de cálculo como se aquêle tributo fôsse devido, obedecidas as percentagens previstas neste artigo.

$\S 4$ is entidades de fins não lúcrativos, que tenham empregados assim definidos pela Legislação TrabàIhista, contribuirão para o Fundo na forma da lei.

§ 5 A Caixa Econômica Federal resolverá os casos omissos, de acôrdo com os critérios fixados pelo Gonselho Monetário Nacional.

Art. 4: O Conselho Monetário Nacional poderá alterar, até cinqüenta por 
cento $(50 \%)$, para mais ou para menos, os percentuais de contribuição de que trata $\circ \S 2$ ? do art. 3 , tendo em vista a proporcionalidade das contribuiçōes.

Art. 5? A Caixa Econômica Federal emitirá, em nome de cada empregado, uma Caderneta de Participação Programa de Integração Social - movimentável na forma dos artigos $8{ }^{\circ} e$ 9ọ desta Lei.

Art. 6! A efetivação dos depósitos no Fundo correspondente à contribuição referida na alínea "b" do artigo 3 ? será processada mensalmente a partir de $1^{\circ}$ de julho de 1971.

Parágrafo único. A contribuição de julho será calculada com base no faturamento de janeiro; a de agôsto, com base no faturamento de fevereiro; $e$ assim sucessivamente.

Art. 70 A participação do empregado no Fundo far-se-á mediante depósitos efetuados em contas individuais abertas em nome de cada empregado, obedecidos os seguintes critérios:

a) $50 \%$ (cinqüenta por cento) do valor destinado ao Fundo será dividido em partes proporcionais ao montante de salários recebidos no período;

b) os $50 \%$ (cinqüenta por cento) restantes serão divididos em partes proporcionais aos qüinqüênios de serviços prestados pelo empregado.

$\S$ 1? Para os fins dêste artigo, a Caixa Econômica Federal, com base nas informações fornecidas pelas emprêsas, no prazo de 180 (cento e oitenta) dias, contados da publicação desta Lei, organizará um Cadastro Geral dos participantes do Fundo, na forma que fôr estabelecida em regulamento.
$\S 2$. A omissão dolosa de nome de empregado entre os participantes do Fundo sujeitará a emprêsa a multa em benefício do Fundo, no valor de 10 (dez) meses de salários, devidos ao empregado cujo nome houver sido omitido.

$\S 3$ ? Igual penalidade será aplicada em caso de declaração falsa sôbre o valor do salário e do tempo de serviço do empregado na emprêsa.

Art. 8? As contas de que trata o artigo anterior serão também creditadas:

a) pela correção monetária anual do saldo credor, na mesma proporção da variação fixada para as Obrigaçōes Reajustáveis do Tesouro Nacional;

b) pelos juros de $3 \%$ (três por cento) ao ano, calculados, anualmente, sôbre o saldo corrigido dos depósitos;

c) pelo resultado líquido das operações realizadas com recursos do Fundo, deduzidas as despesas administrativas e as provisōes e reservas cuja constituição seja indispensável, quando o rendimento fôr superior à soma dos itens $\mathbf{a} \mathbf{e} \mathbf{b}$.

Parágrafo único. A cada período de um ano, contado da data da abertura da Conta, será facultado ao empregado o levantamento do valor dos juros, da correção monetária contabilizada no período e da quota parte produzida pelo item $c$ anterior, se existir.

Art. 9? As importâncias creditadas aos empregados nas cadernetas de participação são inalienáveis e impenhoráveis, destinando-se, primordialmente, à formação de patrimônio do trabalhador. 
$\S 1$ Por ocasião de casamento, aposentadoria ou invalidez do empregado titular da conta poderá o mesmo receber os valôres depositados, mediante comprovação da ocorrência, nos têrmos do regulamento; ocorrendo a morte, os valôres do depósito serão atribuidos aos dependentes, e em sua falta, aos sucessores na forma da Lei.

§ 2: A pedido do interessado, o saldo dos depósitos poderá ser também utilizado como parte do pagamento destinado à aquisiçăo da casa própria, obedecidas as disposições regulamentares previstas no art. 11.

Art. 10. As obrigações das emprêsas, decorrentes desta Lei, são de caráter exclusivamente fiscal, não gerando direitos de natureza trabalhista nem incidência de qualquer contribuição previdenciária em relação a quaisquer prestações devidas, por lel ou por sentença judicial ao empregado.

Parágrafo único. As importâncias incorporadas ao Fundo não se classificam como rendimento do trabalho, para qualquer efeito da Legislação Trabalhista, de Previdência Social ou Fiscal e não se incorporam aos salários ou gratificações, nem estão sujeitas ao impôsto sôbre a renda e proventos de qualquer natureza.

Art. 11. Dentro de 120 (cento e vinte) dias, a contar da vigência desta Lei, a Caixa Econômica Federal submeterá à aprovação do Conselho Monetário Nacional o Regulamento do Fundo, fixando as normas para o recoIhimento e a distribuição dos recursos, assim como as diretrizes e os critérios para a sua aplicação.
Parágrafo único. O Conselho Monetário Nacional pronunciar-se-á, no prazo de 60 (sessenta) dias, a contar do seu recebimento, sôbre o Projeto de regulamento do Fundo.

Art. 12. As disposições desta Lei não se aplicam a quaisquer entidades integrantes da administraçăo pública federal, estadual ou municipal, dos territórios e do Distrito Federal, direta ou indireta, adotando-se, em todos os niveis, para efeito de conceituação, como entidade da Administração Indireta, os critérios constantes dos Decretos-leis n?s 200, de 25 de fevereiro de 1967, e 900, de 29 de setembro de 1969.

Art. 13. Esta Lel Complementar entrará em vigor na data de sua publicação.

Art. 14. Revogam-se as disposiçōes em contrário.

Brasília, 7 de setembro de 1970. 149 \% da Independência e $82^{\circ}$ da República.

EMÍLIO G. MÉdICI

Alfredo Buzaid

Adalberto de Barros Nunes

Orlando Geisel

Mário Gibson Barboza

Antônio Delfim Netto

Mário David Andreazza

L. F. Cirne Lima

Jarbas G. Passarinho

Júlio Barata

Márcio de Souza e Mello

F. Rocha Lagôa

Marcus Vinicius Pratini de Moraes

Antônio Dias Leite Júnior

João Paulo dos Reis Velloso

José Costa Cavalcanti

Hygino C. Corsetti 